\title{
Causes and patterns of morbidity and mortality in Afghanistan: Joint estimation of multiple causes in the neonatal period
}

\author{
Oyelola A. Adegboye ${ }^{1}$ \\ Danelle Kotze
}

\begin{abstract}
This paper focuses on investigating the leading cause(s) of death and preventable factors in Afghanistan, using data from verbal autopsies of infant deaths. We are of the view that the presence of a disease in a person may increase the risk of another disease that may contribute to the death process. The influence of individual- and community-level variables on infant morbidity and mortality in Afghanistan is examined. The results of this study suggest the existence of multiple causes of death in the Afghanistan Mortality Survey (AMS). In Afghanistan, complications of pregnancy are clearly a problem and must be adequately improved.
\end{abstract}

Keywords: Afghanistan mortality survey; morbidity and mortality; verbal autopsy; multiple causes of death; spatial-bivariate probit models.

\section{Résumé}

Cet article porte sur une recherche des principales causes de mortalité et des facteurs évitables en Afghanistan réalisée à partir de données provenant d'autopsies verbales d'enfants morts. Nous sommes d'avis que la présence d'une maladie chez une personne augmente le risque qu'une autre maladie vienne contribuer au processus de sa mort. L'influence de variables, individuelles et communautaires, sur la morbidité et mortalité infantile en Afghanistan a été examinée. Les résultats de cette étude indiquent l'existence de multiples causes de décès dans Afghanistan Mortality Survey (AMS). En Afghanistan, il est clair que les complications pendant la grossesse posent un problème et que la situation doit être corrigée.

Mots-clés : sondage sur la mortalité en Afghanistan, morbidité et mortalité; autopsie verbale, causes multiples de décès, modèles de probits spatiaux à deux variables.

\section{Introduction}

Most information on medical history is provided on death certificates or in vital registration systems, which may not be available in some developing countries. Measuring cause-specific mortal-

1. Oyelola A. Adegboye, Department of Mathematics, Statistics, and Physics, Qatar University, Doha, Qatar. Email: oyeadegboye@yahoo.com; and Danelle Kotze, Department of Statistics and Population Studies, University of the Western Cape, South Africa. 
ity rates is very difficult in this situation, especially where vital registration systems are lacking for the majority of the population. Providing good analysis and estimates for cause-specific mortality is essential for understanding the overall profile and burden of disease in a population (Bickel et al. 2006). To resolve issues around death certificate and vital registration data, many countries have set up mortality surveillance systems that provide community-based death reviews to explore the medical and non-medical causes of death. Such reviews identify personal, family, and community factors that may have contributed to the death process.

The verbal autopsy (VA) has been used to estimate cause-specific mortality in a variety of methodological settings, the most common being in the context of an epidemiological study (Quigley 2005). There is a substantial and growing body of literature on the reliability and validity of VA; it provides accurate cause of death, especially in the absence of a death certificate or vital registration (Bapat et al. 2012; King and Lu 2008; Lee et al. 2008; Quigley 2005; Sibai et al. 2001; Philip et al. 2005). The use of a questionnaire for VA has an advantage over ad hoc investigations because of its high specificity when the list of target diseases is extensive (Fauveau 2005; Garenn and Fauveau 2006). The World Health Organization has a long history of structured questionnaires for systematic recording of signs and symptoms in assessing causes of death (WHO 1978, 1995).

Afghanistan has been devastated by armed conflicts for about three decades now, and has seen over 5 million people been displaced during this period (Bhutta 2002). This has resulted in a barely functioning health care system and, in some areas, non-availability of health care facilities. Afghanistan has about a 43 per cent child population, and the country has a physician density of about 21 physicians to 100,000, where about two-thirds of the physicians live and work around Kabul. There is limited literature on infant and child mortality in Afghanistan, with most research conducted at the provincial or regional level due to security and logistic reasons. Moreover, most mortality statistics and data in Afghanistan were collected in the past decade. For instance, in their study, Kim et al. (2012) assess the caesarean section deliveries across secure sites in 31 out of the 34 provinces in Afghanistan, Amowitz et al. (2002) conducted a cross-sectional survey of 4,886 Afghan women living in 7 districts in Afghanistan's Herat province, while Mayhew et al. (2008) conducted a cross-sectional study in all 33 provinces in 2004. A retrospective cohort study of women of reproductive age (15-49 years) was done by Bartlett et al. in 2002 in four districts of Kabul province, Laghman province, Kandahar province, and Badakshan province (Bartlett et al. 2005). Gessner (1994) surveyed 312 displaced families and 300 resident families in Kabul to assess their mortality rates.

The high rates of maternal and perinatal mortality in Afghanistan were attributed to low rates of caesarean sections (CS), and many cases of CS were either emergencies or referrals from another health care facility (Kim et al. 2012). Barlett et al. (2005) reported that only 13 per cent of respondents in their study had used skilled birth attendants during delivery. Diarrhoea and acute respiratory infections are responsible for about 36 per cent of the childhood deaths in Afghanistan (Gessner 1994; Prasad 2006). Barlett et al. (2005) investigated the deaths among women of reproductive age through verbal-autopsy interviews of family members. Their study revealed that remoteness played a significant role in increasing maternal mortality in Afghanistan. Other risk factors for high child and maternal mortality rates in the country include: home delivery $(90$ per cent of total births are without medical assistance; Nelson 2011), and poor sanitation and lack of access to clean water have an indirect relation to high infant mortality in Herat province (Amowitz et al. 2002). Gessner (1994) found injuries sustained directly as a result of war to be the most common cause of death in the displaced and resident population in Kabul. Most of these studies are restricted to district level or provincial level, and also neglected the possibility that mortality rates may be spatially dependent. 
Adegboye and Kotze: Causes and patterns of morbitidy and mortality in Afghanistan

In some cases, death is a result of the cumulative effects of different causes, where some ailment may not directly contribute to the death process and therefore is not included as the underlying cause of death. For instance, the presence of a chronic disease in a person may increase the risk of developing another related disease that may contribute to the death process. Moreover, the causes of death are not listed in the Afghanistan Mortality Survey (AMS) data; rather, the diseases leading to the death of the household member were listed. We are of the opinion that there may exist correlations between multiple causes of death; ignoring such vital information may bias the mortality estimates, and thus, their simultaneous effects must be jointly investigated.

The main idea of this paper is to investigate the associations between diseases and possible causes of death. This will allow the possibility of identifying a range of illnesses that may have contributed to the death process, thereby providing comprehensive information. The study will investigate the influence of some demographic variables and risk factors (e.g., remoteness, wealth index, residence, sanitation, access to safe and clean water) on morbidity and mortality. Risk factors for multiple causes of death will be simultaneously analyzed. As in most health outcomes, geographical variations cannot be ruled out and risk factors may vary geographically (Neelon et al. 2012). Thus, this study addresses the issue of spatial dependency between provinces, by extending the bivariate probit model to incorporate spatial information, where the spatial dependency was handled through random effects in order to investigate if associations among different causes of death, dependent on certain demographic variables, varied geographically. The study, to the best of our knowledge, is the first empirical analysis on the use of VA in Afghanistan, and the first to provide multiple causes of death analysis using the AMS data sets.

The rest of the paper is organized as follows: The next section presents the data sources and methodology, describes the data, explains the disease classification, and outlines the proposed multivariate analysis model. Then, a general empirical application will be introduced, and a summary of the results of an in-depth analysis of the neonatal mortality data will be presented. We conclude the paper with a discussion and conclusions from the study.

\section{Methods}

\section{Data used in this study}

The data used in this research is part of the Afghanistan Mortality Survey (AMS 2010), which is the first nationwide survey of its kind in Afghanistan. The survey was conducted in 2010 by the Afghan Public Health Institute (APHI) of the Ministry of Public Health (MoPH) and the Central Statistics Organization (CSO), with technical and logistic support from ICF Macro and the Indian Institute for Health Management Research (IIHMR; APHI/MoPH et al. 2011). The AMS is a special survey that focused on mortality, causes of death, and maternal mortality. The survey covered about 87 per cent of the country and all 34 provinces of Afghanistan.

The AMS centres on data from verbal autopsies (VA) of deaths within a household up to three years beforehand (2007-2010). A team of fifteen physicians participated in the study; they underwent special training in the WHO International Classification of Death (ICD10; WHO 2011) to assign causes of death. Three types of questionnaires were used for the verbal autopsies (VA): death of an infant aged 0-28 days (VA1), death of a child aged 29 days-11 years (VA2), and death of an adult aged 12 years and above (VA3). The respondents were key informants that were present at the time of death; they were allowed to provide an open narrative section to describe 
verbatim the illness and events that led to the death. The VA questionnaires included a wide range of questions on signs and symptoms during the disease or injury preceding the death, and were reviewed independently by two physicians (APHI/MoPH et al. 2011). Also, the VA provided information on medications used, utilization of health services, and behavioural and environmental risk factors. In addition to basic information about the respondent, information on the deceased, date/place of death, and delivery history were collected in the verbal autopsies of death, as well as data on maternal and child health, childhood mortality, wealth index, ownership of basic facilities, and availability of health facilities at household and/or individual levels. The data sets consist of VA from 1,105 neonatal (0-28 days), 997 perinatal and children (29 days-11 years), and 1,831 adult deaths (above 12 years). The list, as well as summary statistics of some of the variables used in this study, are provided in Table 1.

\section{Classification of diseases}

The classification of causes of death was done using the International Classification of Disease (ICD; WHO 2011), which is designed to promote international comparability in the collection, processing, classification, and presentation of mortality statistics. For easy comparison and interpretability of results, classification of the diseases was done in the following manner. All causes of death due to infections or parasitic infestations were classified as INFECTIOUS (INF). Diseases encompassing primary systemic diseases like neoplasm, diseases of the blood and blood-forming organs, diseases of the nervous system, sensory organs, circulatory system, respiratory system, digestive system, genitourinary system, skin and subcutaneous tissue, and musculoskeletal system and connective tissue were classified as NON-INFECTIOUS (NNN). Also, all deaths related to pregnancy, childbirth, and the puerperium and conditions that have their origin in the perinatal period even though death or morbidity occurs later were classified as COMPLICATIONS (COMP). Other classifications were endocrine, nutritional, and metabolic diseases as ENM, and mental and behavioural disorders, which were classified as MENTAL. Also symptoms, signs, and ill-defined conditions were classified as SYMPTOMS (SSID), while injury, poisoning, and certain other consequences of external causes were classified as INJURY (INJ).

Although it is important to understand the specific cause of death independently, the interactions between causes offer information whose value cannot be overemphasized. Let us suppose we have $\mathrm{N}$ main causes of death, each with a YES/NO response. This will give $2^{\mathrm{N}}-1$ possible combinations of multiple causes, excluding the case where both responses are NO. These combinations will have different implications in terms of effect on demographic variables, and will provide a very important understanding of their occurrence in the population.

\section{Data analysis}

Exploratory analysis was based on cross-tabulation of statistics (frequencies/percentages) from the mortality data. Analyses were carried out on the contingency tables using the Cochran-MantelHaenszel chi-squared test. The dimensions of the tables were defined by the number of causes of death. The analysis was used to investigate the association between causes of death.

A simultaneous analysis of causes of death was modelled by multivariate probit, which is appropriate when correlated binary responses (causes of death) are regressed on explanatory variables (demographic variables and risk factors; Lesaffre and Molenberghs 1991). Considering the modelling 
of joint probability in the bivariate case, ${ }^{2}$ the two equations for a multivariate probit model with three response variables are given as:

$$
\begin{aligned}
& Y_{i j m}^{*} \mid \phi_{i m}=\beta_{m}^{\prime} X_{i j m}+\phi_{i m}+\varepsilon_{i m}, \quad m=1,2 ; i=1, \ldots, 34 ; j=1, \ldots, n_{i} \\
& Y_{i j m}= \begin{cases}1, & \text { if } Y_{i j m}^{*}>0 \\
0, & \text { if } Y_{i j m}^{*}<0\end{cases}
\end{aligned}
$$

where the continuous $Y_{i j m}^{*}$ is an unobservable latent variable related to dichotomous response $Y_{i j m}$ via the threshold concept. $Y_{i j m}=1$ implies that individual $j$ in province $i$ dies of cause $m$, and $Y_{i j m}=0$ implies otherwise - that is, an unobserved variable representing the latent variable, which represents the probability of each disease classification $m$ vs not, with the latent vector having a 2-dimensional normal distribution. $X_{i j m}$ is a vector of covariates associated with disease classification $m, \beta_{m}$ is the parameter to be estimated, and $\phi_{i m} ; m=1,2$ is the vector of spatially dependent random effects for the province $i$, which is distributed as multivariate normal with a mean of zero and variance-covariance matrix $\Sigma ; \varepsilon$ is the error term, where $\varepsilon_{i m} \sim$ i.i.d. $\mathrm{N}(0, \Omega)$,

$$
\Omega=\left(\begin{array}{l}
\tau_{1}^{2} \\
\tau_{21} \tau_{2}^{2}
\end{array}\right) \text { and } \Sigma=\left(\begin{array}{l}
\sigma_{1}^{2} \\
\sigma_{21} \sigma_{2}^{2}
\end{array}\right) .
$$

The two error terms can be written as:

$$
\eta_{i m}=\phi_{i m}+\varepsilon_{i m}
$$

From the above assumptions, $\operatorname{Var}\left(\eta_{i m}\right)=\tau_{m}^{2}+\sigma_{m}^{2}$; this implies that within units $\eta_{i m}{ }^{\prime} s$ will be correlated:

$$
\operatorname{Corr}\left(\eta_{i m}, \eta_{i m^{\prime}}, m \neq m^{\prime}\right) \equiv \rho=\frac{\tau_{21}^{2}+\sigma_{21}^{2}}{\left\{\left(\tau_{m}^{2}+\sigma_{m}^{2}\right)\left(\tau_{m^{\prime}}^{2}+\sigma_{m^{\prime}}^{2}\right)\right\}^{1 / 2}}
$$

For simplicity, let us assume that the two disease classifications are the main causes of death. The joint probability can be written as:

$$
\operatorname{Pr}\left(Y_{1}=1, Y_{2}=1 \mid \phi_{i m}\right)=\int_{A_{1}} \int_{A_{2}} \varphi\left(\beta_{m}^{\prime} X_{i j m}+\phi_{i m}, \Sigma\right) d y_{1} d y_{2}
$$

where $\varphi$ is the density function of a multivariate normal distribution and $A_{m}$ is the interval $\left(-\infty, \beta_{i m}^{\prime} X_{i j m}\right)$.

2. Two major causes of death each with Yes/No response will result in 3 possible combinations of multiple outcomes, excluding the NO-NO combination. 


\section{Results}

We begin our analysis with an explorative summary of the 1,105 neonatal deaths, 997 perinatal and child, and 1,831 adult deaths in the AMS data. The results from the combined data sets indicated that two-thirds of urban households fall in the richest quintile, while overall 54 per cent of the households have access to safe drinking water. Also, only one-fifth of the households have an improved toilet facility. The fertility rates are 5.2 and 4.7 children per female for rural areas and urban areas, respectively. Death from pregnancy-related causes is very high (higher in rural areas), with 1 in every 50 women dying of pregnancy-related causes, 2 in 5 pregnancy-related deaths occur during pregnancy, and about 20 per cent within two months after delivery (APHI/MoPH et al. 2011). Injury-related deaths in men were 20 per cent, with half of these deaths being war- and violence-related in 15+ years (APHI/MoPH et al. 2011).

The number of times a specified disease occurs on the verbal autopsy form, as well as some demographic variables, are presented in Table 1 and 2. Among the 1,105 deaths in the neonatal data, about 65 per cent of deceased were reported to have had complications of pregnancy, childbirth, and the puerperium (Table 2). Because of these complications, babies are born before term-due to early end of pregnancy (39 per cent), prematurity (40.6 per cent), cases of low birth weight (44 per cent), and a few cases of malformation. Thus, diseases classified as complications (i.e., complications of pregnancy, childbirth, and the puerperium) are the most common cause of neonatal death. Table 3 reflects the number of deaths, with the indicated combinations of causes of death. Complications alone occurred in about 54 per cent of all neonatal deaths, while solely symptomatic diseases occurred in about 6 per cent of cases (Table 3). Among the 997 perinatal deaths, the most common cause of death was diseases classified as infectious and parasitic (e.g., diarrhoea, fever, cough and tuberculosis), which constitutes 88 per cent of all deaths in this age group. Also, 82 per cent of the deceased in perinatal were reported to have had diseases classified as symptomatic conditions (symptoms, signs, and ill-defined conditions) prior to their death. Infectious and parasitic diseases and/or symptomatic conditions together constitute about 25 per cent of all deaths in this category.

Out of the 1,831 adults deaths, the verbal autopsy revealed that 98 per cent of them reported to have had diseases classified as non-infectious/non-communicable and neoplasm (NNN). About 28 per cent of adult deaths were reported to have been jointly caused by diseases in the three major classifications: non-infectious, infectious, and symptomatic conditions. Deaths of adults generally exceed neonatal and perinatal; for instance, in Kabul 58.7 per cent of the deaths occurred in adults (Figure 1). Also noted was a geographical heterogeneity in the distribution of neonatal complications at birth and the puerperium (Figure 2).

We conducted a separate in-depth analysis of the neonatal data. Exploratory data analysis of the contingency table was used to assess whether single-cause analysis would be appropriate or not. The Cochran-Mantel-Haenszel chi-square test statistics for independence of causes of death (binary responses) showed a strong association among the variables ( $p$-value $<0.0001)$. From this result, we further explored the association between the two most common causes of death: complications and symptomatic conditions. The percentage of deaths involving the complications, which also include symptomatic diseases, was calculated to be 7.3 per cent. The percentage was smaller than would be expected if the two causes were occurring independently in the death population. The chi-squared test for independence is statistically highly significant, indicating that the two causes are not independent. These results showed a clear association between causes of death and the appropriateness of multiple-cause analysis to capture the association between different causes of death and, thus, the use of the bivariate probit model. 
Adegboye and Kotze: Causes and patterns of morbitidy and mortality in Afghanistan

Table 1. Characteristics of deaths in the three age group and summary of the risk factors.

\begin{tabular}{|c|c|c|c|c|c|c|}
\hline \multirow{2}{*}{ Variables } & \multicolumn{2}{|c|}{ Neonatal } & \multicolumn{2}{|c|}{ Perinatal and children } & \multicolumn{2}{|r|}{ Adults } \\
\hline & $\mathrm{N}$ & $\%$ & $\mathrm{~N}$ & $\%$ & $\mathrm{~N}$ & $\%$ \\
\hline Disease classification: Infectious & 220 & $19.91^{*}$ & 874 & $87.66^{*}$ & 989 & $54.01 *$ \\
\hline Complications & 713 & $64.52 *$ & 140 & $14.04 *$ & 111 & $6.06^{*}$ \\
\hline Non-infectious & 40 & $3.62 *$ & 280 & $28.08 *$ & 1798 & $98.2 *$ \\
\hline Symptoms & 290 & $26.24 *$ & 821 & $82.35 *$ & 1433 & $78.26^{*}$ \\
\hline Injury & 65 & $5.88 *$ & 393 & $39.42 *$ & 711 & $38.83 *$ \\
\hline Mean age & & 2.5 months & & 5.14 years & & 54.26 years \\
\hline Gender: Male & 624 & 56.62 & 548 & 55.47 & 1045 & 57.26 \\
\hline Female & 478 & 43.38 & 440 & 44.53 & 780 & 42.74 \\
\hline Mother's age (years): $<15$ & 55 & 4.98 & & & & \\
\hline $16-35$ & 898 & 81.27 & & & & \\
\hline$>36$ & 152 & 13.75 & & & & \\
\hline Size at birth: Smaller than normal & 431 & 43.98 & & & & \\
\hline Normal & 493 & 50.31 & & & & \\
\hline Larger than normal & 56 & 5.71 & & & & \\
\hline Place of birth: Home & 680 & 61.87 & & & & \\
\hline Hospital & 419 & 38.13 & & & & \\
\hline Antenatal: Yes & 522 & 48.47 & & & & \\
\hline No & 555 & 51.53 & & & & \\
\hline Single or multiple birth: Yes & 1025 & 93.01 & & & & \\
\hline No & 77 & 6.99 & & & & \\
\hline Duration of pregnancy: Pre-term (1-9 months) & 438 & 39.63 & & & & \\
\hline On term (9 months) & 611 & 56.25 & & & & \\
\hline$>9$ months & 41 & 3.76 & & & & \\
\hline Pregnancy at time of death: Yes & & & & & 415 & 15.89 \\
\hline No & & & & & 217 & 84.11 \\
\hline Smoker: Yes & & & & & 256 & 14.17 \\
\hline No & & & & & 1551 & 85.83 \\
\hline Small at birth: Yes & & & 140 & 30.11 & & \\
\hline No & & & 325 & 69.89 & & \\
\hline Malnutrition: Yes & & & 174 & 17.45 & 208 & 11.36 \\
\hline No & & & 809 & 81.14 & 1594 & 87.04 \\
\hline Residence: Urban & 320 & 28.96 & 210 & 21.06 & 618 & 33.75 \\
\hline Rural & 785 & 71.04 & 787 & 78.94 & 1213 & 66.25 \\
\hline Region: North Eastern & 166 & 15.02 & 176 & 17.65 & 263 & 14.36 \\
\hline Northern & 161 & 14.57 & 158 & 15.85 & 335 & 18.3 \\
\hline Western & 142 & 12.85 & 140 & 14.04 & 230 & 12.56 \\
\hline Central Highlands & 32 & 2.9 & 21 & 2.11 & 40 & 2.18 \\
\hline Capital & 188 & 17.01 & 142 & 14.24 & 361 & 19.72 \\
\hline Eastern & 181 & 16.38 & 158 & 15.85 & 260 & 14.2 \\
\hline Southern & 109 & 9.86 & 89 & 8.93 & 195 & 10.65 \\
\hline South Eastern & 126 & 11.4 & 113 & 11.33 & 147 & 8.03 \\
\hline Sanitation: Bad & 888 & 80.36 & 824 & 82.65 & 1394 & 76.13 \\
\hline Good & 217 & 19.64 & 173 & 17.35 & 437 & 23.87 \\
\hline Source of water: Unsafe & 473 & 42.81 & 442 & 44.33 & 754 & 41.18 \\
\hline Safe & 632 & 57.19 & 555 & 55.67 & 1077 & 58.82 \\
\hline Wealth index: Poorest & 245 & 22.17 & 232 & 23.27 & 345 & 18.84 \\
\hline Poorer & 218 & 19.73 & 206 & 20.66 & 373 & 20.37 \\
\hline Middle & 202 & 18.28 & 167 & 16.75 & 369 & 20.15 \\
\hline Richer & 224 & 20.27 & 201 & 20.16 & 360 & 19.66 \\
\hline Richest & 216 & 19.55 & 191 & 19.16 & 384 & 20.97 \\
\hline Remoteness: Most remote & 261 & 23.62 & 268 & 26.88 & 443 & 24.19 \\
\hline Least remote & 130 & 11.76 & 112 & 11.23 & 251 & 13.71 \\
\hline Total number of deaths: 1 & 764 & 69.14 & 770 & 77.23 & 1461 & 79.79 \\
\hline$>2$ & 341 & 30.86 & 227 & 22.77 & 370 & 20.21 \\
\hline
\end{tabular}

* Includes other disease classifications as well, that is, the union of disease interaction. 
Table 2. Observed frequency of the disease profile by age group in the study.*

\begin{tabular}{|c|c|c|c|c|}
\hline Categories(ICD)/Diseases & & $\begin{array}{c}\text { Neonatal } \\
(1,105)\end{array}$ & $\begin{array}{c}\text { Perinatal } \\
(997)\end{array}$ & $\begin{array}{l}\text { Adults } \\
(1,831)\end{array}$ \\
\hline \multicolumn{5}{|l|}{ Symptoms and signs } \\
\hline Vomited & & 83 & & 452 \\
\hline Distension & & 70 & & \\
\hline Breathe difficulties & & 166 & & \\
\hline \multirow[t]{2}{*}{ Headaches } & & & 155 & 726 \\
\hline & Total & $290(26.3 \%)^{*}$ & $821(82.3 \%)^{*}$ & $1433(78.3 \%)^{*}$ \\
\hline \multicolumn{5}{|c|}{ (5) } \\
\hline Fever & & 186 & 650 & 778 \\
\hline Cough & & 67 & 360 & 83 \\
\hline Diarrhoea & & 36 & 316 & 234 \\
\hline Tuberculosis & & & 4 & 131 \\
\hline \multirow[t]{2}{*}{ Excessive bleeding } & & & & 73 \\
\hline & Total & $220(19.9 \%)^{*}$ & $874(87.7 \%)^{*}$ & $989(54.0 \%)$ \\
\hline \multicolumn{5}{|l|}{ Injury } \\
\hline Any injury at birth & & 65 & & \\
\hline \multirow[t]{2}{*}{ Injury and accident } & & & 393 & 711 \\
\hline & Total & $65(5.8 \%)^{*}$ & $393(39.4 \%)^{*}$ & $711(38.8 \%)^{*}$ \\
\hline \multicolumn{5}{|l|}{ Non-infectious } \\
\hline Paralysis & & 15 & 40 & \\
\hline Rash & & 28 & & \\
\hline Heart & & & 83 & \\
\hline Bleeding from nose & & & 874 & \\
\hline Asthma & & & 122 & 579 \\
\hline Convulsion & & & 142 & \\
\hline Epilepsy & & & & 71 \\
\hline \multirow{2}{*}{ High blood pressure } & & & & 697 \\
\hline & Total & $40(3.6 \%) *$ & $280(28.1 \%)^{*}$ & $789(43.1 \%)^{*}$ \\
\hline \multicolumn{5}{|l|}{ Complications } \\
\hline Malformation & & 51 & & \\
\hline Premature & & 449 & 140 & \\
\hline \multirow[t]{2}{*}{ End of pregnancy } & & 431 & & \\
\hline & Total & $713(54.5 \%)^{*}$ & $140(14.1 \%)^{*}$ & \\
\hline \multicolumn{5}{|c|}{${ }^{2}$} \\
\hline Diabetes & & & 194 & 194 \\
\hline \multirow[t]{2}{*}{ Malnutrition } & & & 174 & 208 \\
\hline & Total & & $368(36.9 \%)^{*}$ & $402(22 \%) *$ \\
\hline \multicolumn{5}{|l|}{ MENTAL } \\
\hline Mental & & & & 342 \\
\hline 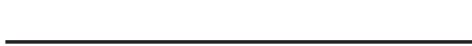 & Total & & & $342(18.7 \%)^{*}$ \\
\hline
\end{tabular}

Table 3. Percentage of overlapping disease classification for Neonatal data (Two-way classification*).

\begin{tabular}{|c|c|c|c|c|}
\hline & Complications Non-infectious & Symptoms & Injury & Infectious \\
\hline Complications & $53.57^{\dagger}$ & 7.3 & 2.9 & 3.9 \\
\hline Non-infectious & $0.09^{\dagger}$ & 2.5 & 0.54 & 1.7 \\
\hline Symptoms & & $5.79^{\dagger}$ & 2.35 & 5.74 \\
\hline Injury & & & $1.18^{\dagger}$ & 1.27 \\
\hline Infectious & & & & $3.71^{\dagger}$ \\
\hline
\end{tabular}




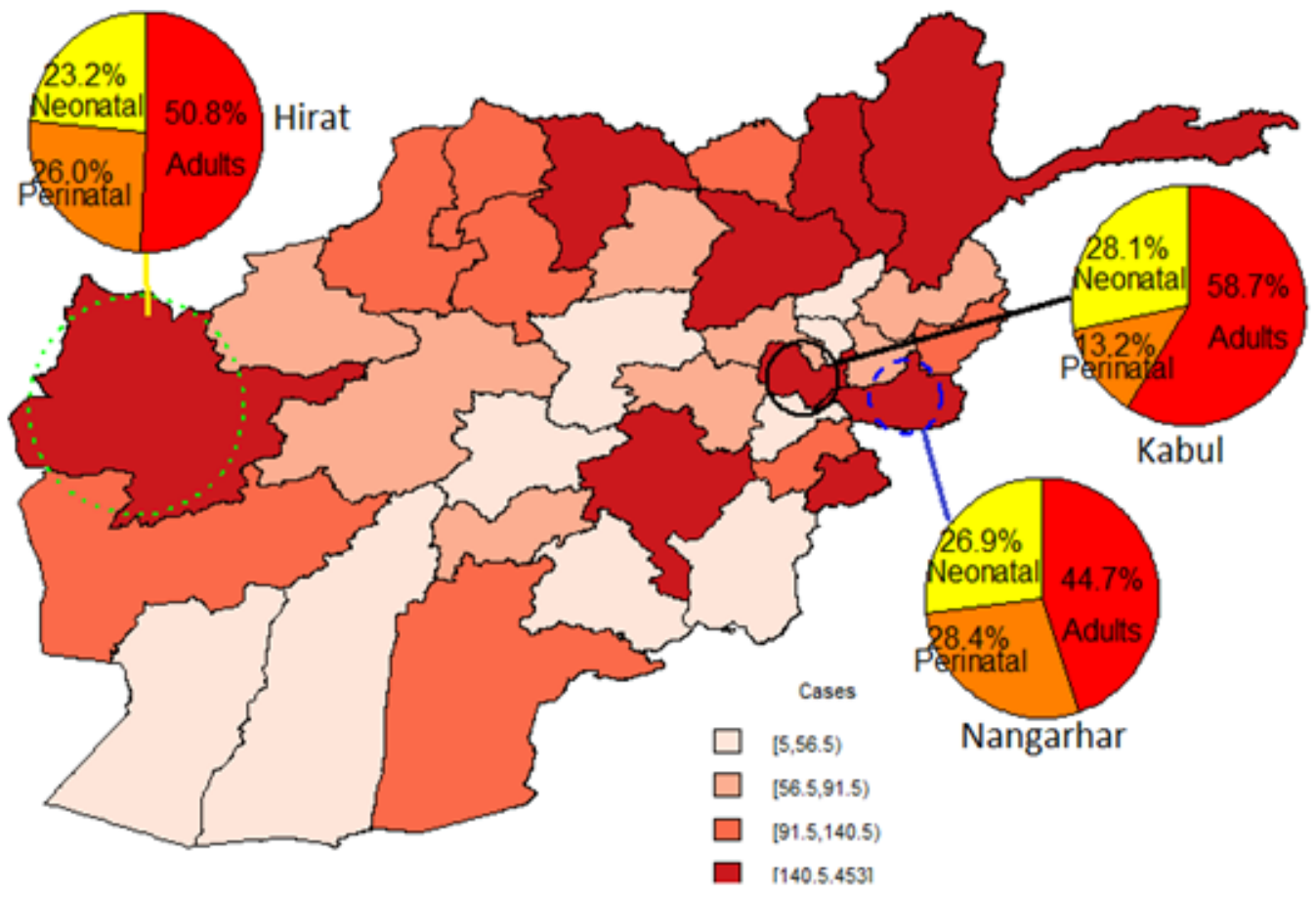

Figure 1. Map of Afghanistan showing the distribution of mortality. The pie chart indicates the breakdown of the proportion of deaths from neonatal, perinatal and child, and adults in the provinces with the top three mortality rates.

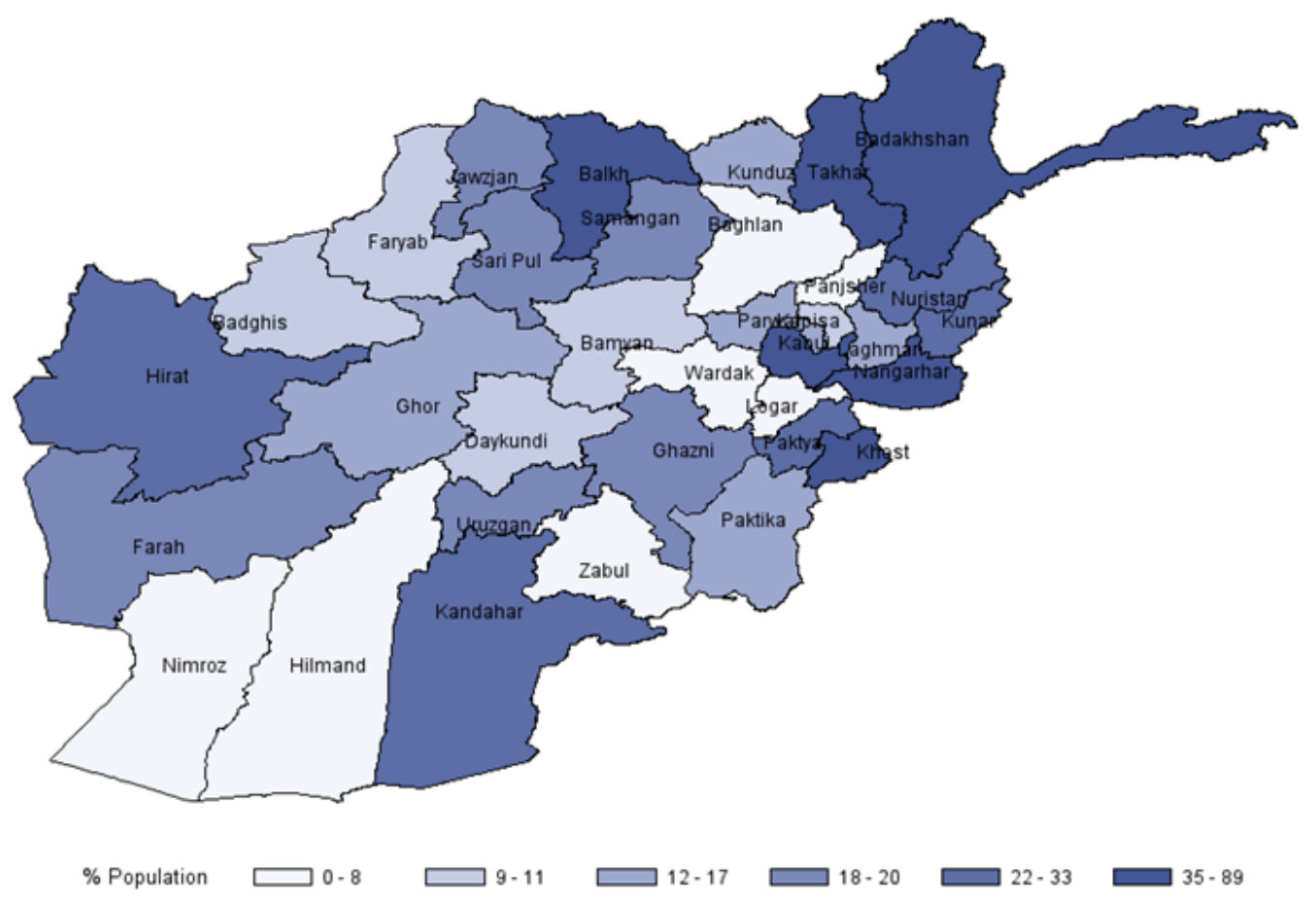

Figure 2. Spatial distribution of percentage of the population with complications in the neonatal data. 
The bivariate probit model was applied to the neonatal data. The results illustrated in Table 4 suggest a number of highly significant risk factors for diseases classified as complications and symptomatic conditions. The spatial bivariate model that accommodates the spatial random effects (Model 3) was compared with the other two models, which are similar to that of Neelon et al. (2012). They

(Models $1 \& 2$ ) include an independent spatial bivariate probit model $\left(\rho=0, \sigma_{12}=0\right)$ and a model with uncorrelated spatial random effects $\left(\sigma_{12}=0\right)$.

Joint probabilities of diseases classified as complications and symptoms were computed considering remoteness index, place of residence, age of the child, size at birth, place of birth, wealth index, sanitation, and mother's age as risk factors. The Akaike Information Criteria (AIC) were used to assess the performance of the three models. The results showed that the model which incorporates spatial-level dependency and other risk factors best describes the joint probabilities of diseases classified as complications and symptoms based on smaller AIC. In Table 4, the efficiency of the parameter estimates increased after the inclusion of correlated random effects. The independent model showed that remoteness index, residence, wealth index, place of birth, and sanitation are not associated with the risk of symptoms and complications, but these risk factors were associated in the uncorrelated and correlated spatial models, respectively. The standard errors also decreased and thereby produced larger parameter estimates. The differences observed in the estimates among the Models 1-3 are due to the incorporation of spatial correlations in Model 3.

Table 4: Spatial bivariate probit model fitted to the neonatal mortality.

\begin{tabular}{|c|c|c|c|c|c|c|}
\hline \multirow{2}{*}{ Risk factors } & \multicolumn{2}{|c|}{ Independent } & \multicolumn{2}{|c|}{ Uncorrelated } & \multicolumn{2}{|c|}{ Correlated } \\
\hline & Estimate & P-value & Estimate & P-value & Estimate & P-value \\
\hline \multicolumn{7}{|l|}{ Symptoms } \\
\hline Remoteness: Most remote & 0.0299 & 0.5281 & 0.0323 & 0.4853 & 0.0053 & 0.9056 \\
\hline Residence: Urban & -0.0154 & 0.8996 & 0.0451 & 0.7408 & -0.0467 & 0.7057 \\
\hline Age & -0.1264 & $<0.0001$ & -0.1022 & $<0.0001$ & -0.1381 & $<0.0001$ \\
\hline Size at birth: Small & -0.2876 & 0.0063 & -0.2131 & 0.0404 & 0.4119 & $<0.0001$ \\
\hline Place of birth: Hospital & 0.1526 & 0.0577 & 0.1431 & 0.1489 & 0.2188 & 0.0033 \\
\hline Wealth Index: Poorest & -0.0919 & 0.0748 & -0.0588 & 0.2811 & 0.0718 & 0.0999 \\
\hline Duration of Pregnancy: & -0.9665 & $<0.0001$ & -1.2412 & $<0.0001$ & 0.7659 & $<0.0001$ \\
\hline Sanitation: Poor & 0.1903 & 0.2061 & 0.1954 & 0.1965 & 0.2749 & 0.0766 \\
\hline Mother's age & -0.0222 & 0.5426 & -0.0108 & 0.7669 & -0.0072 & 0.8268 \\
\hline \multicolumn{7}{|l|}{ Complications } \\
\hline Remoteness: Most remote & 0.0102 & 0.8064 & 0.0101 & 0.8050 & 0.0173 & $<0.0001$ \\
\hline Residence: Urban & 0.1142 & 0.4088 & 0.1088 & 0.3879 & -0.1394 & 0.0146 \\
\hline Age & 0.0504 & $<0.0001$ & 0.0514 & $<0.0001$ & 0.0571 & $<0.0001$ \\
\hline Size at birth: Small & 0.0646 & 0.4018 & 0.0645 & 0.4734 & 0.1289 & 0.0203 \\
\hline Place of birth: Hospital & -0.0373 & 0.7149 & -0.0396 & 0.6446 & -0.0305 & 0.3521 \\
\hline Wealth Index: Poorest & 0.0715 & 0.1540 & 0.0585 & 0.1453 & 0.0785 & 0.0147 \\
\hline Duration of Pregnancy & 0.2953 & $<0.0001$ & 0.2857 & $<0.0001$ & 0.2800 & $<0.0001$ \\
\hline Sanitation: Poor & -0.2681 & 0.0569 & -0.2721 & 0.0571 & 0.3562 & 0.0150 \\
\hline Mother's age & -0.0416 & 0.2056 & -0.0467 & 0.1692 & -0.0558 & 0.0827 \\
\hline$\sigma_{1}^{2}$ & 0.1535 & 0.0580 & 0.05045 & 0.8287 & 0.9368 & $<0.0001$ \\
\hline$\sigma_{2}^{2}$ & -0.1548 & 0.1091 & 0.1012 & 0.3038 & 0.0267 & $<0.0001$ \\
\hline$\sigma_{12}$ & & & & & -0.0251 & $<0.0001$ \\
\hline$\rho=\operatorname{corr}\left(\mathrm{Y}_{\mathrm{j} 11} *,\left.\mathrm{Y}_{\mathrm{ij} 2} *\right|_{\varphi}\right)$ & & & & & -0.5098 & $<0.0001$ \\
\hline$\rho_{\varphi}$ & & & & & -0.7 & $<0.0001$ \\
\hline $\mathrm{AIC}$ & 1896.7 & & 1813.8 & & 1793.6 & \\
\hline
\end{tabular}


We found statistically significant correlations between the two major causes of neonatal deaths (complications and symptoms: p-value <0.0001). The results also indicated an increase in the odds of complications at birth for home delivery ( 35 per cent higher). There exists a significant difference in proportions of complications between poorest families and richest families, and a 7 per cent higher chance of complications at birth for families in the poorest quintile. Additionally, analysis of remoteness indicates a significant difference ( $\mathrm{p}$-value $<0.0001$ ) between families in the most remote areas compared with families in the least remote areas ( 2 per cent higher chance for families in the most remote).

Evidence from the spatial correlated model, as illustrated in Table 4 and Figure 3, indicates that diseases classified as symptoms are prominent. In children delivered at home, there is a 25 per cent higher chance than for hospital delivery; in children that are small at birth there is a 51 per cent higher chance than for normal size; and in families in the poorest quintile there is an 8 per cent higher chance compared to families in the richest quintile.

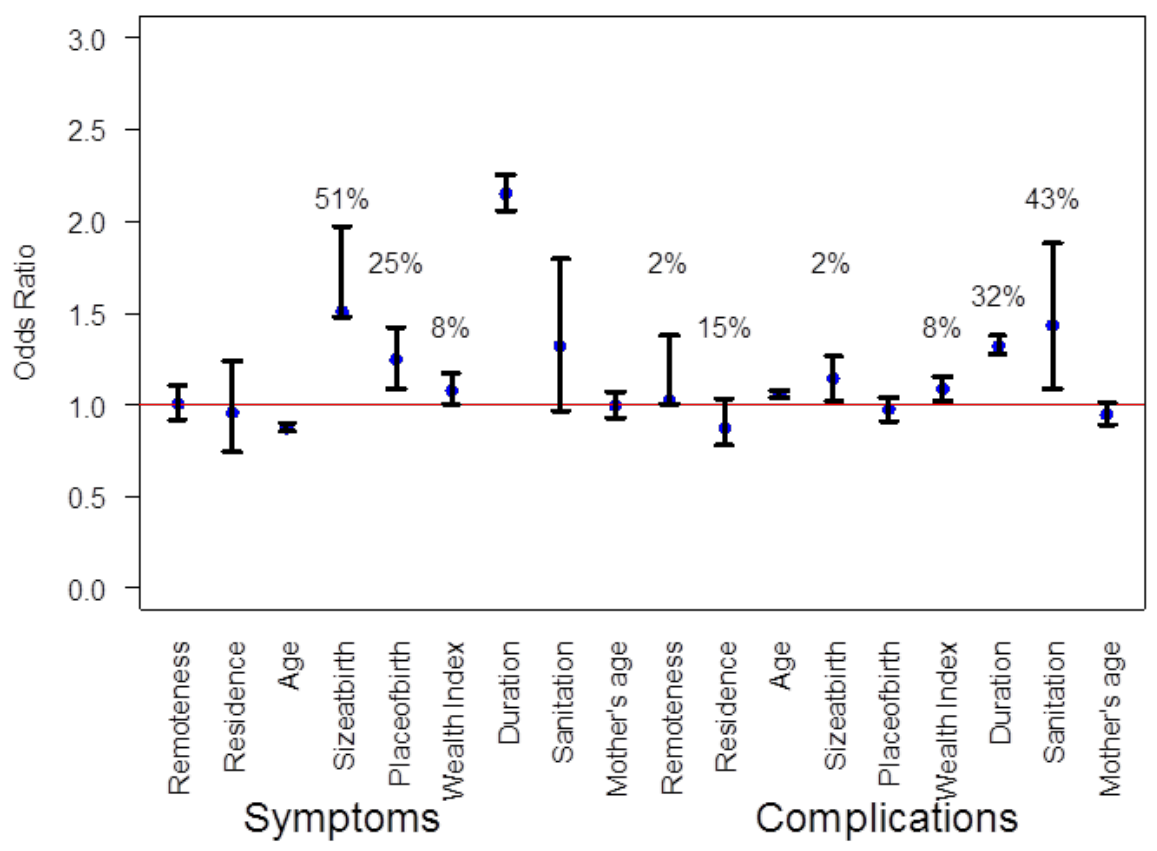

Figure 3: Odds ratio for various risk factors from the correlated spatial bivariate probit model fitted to the neonatal mortality and the percentage chances are shown.

\section{Discussion}

An understanding of the dynamics of cause-specific mortality is crucial in assessing the health of a population. Several diseases may play different roles in the death process, and thus, the concept of multiple analysis. Evaluation of multiple causes of death and risk factors can be done by analyzing their joint probabilities. This study provides an important and crucial empirical study of multiple causes of death in Afghanistan. In this study, the prevalence of multiple cause of death risk factors was investigated in the neonatal population in the AMS 2010, the first national representative and comprehensive mortality survey in Afghanistan. 
Complications at pregnancy and the puerperium and symptomatic conditions are the top two major causes of death in neonatals. It is known that the contribution of different diseases can vary in the mortality process, with some viewed as a lethal sequel of other underlying conditions (Stallard 2002). This study revealed significant information about the strength of association between causes of death.

The availability of no trained or professional birth attendants is common in developing countries, thus the high rates of complications at birth. In Afghanistan, 1 in every 50 women dies of pregnancyrelated causes, with 2 in 5 pregnancy-related deaths occuring during pregnancy and about 20 per cent within two months after delivery (APHI/MoPH et al. 2011). Complications during pregnancy or at birth have serious consequences for the baby and the mother. In this study, 39 per cent of babies are born before term due to early end of pregnancy, 40.6 per cent are born premature, and 44 per cent are born with low birth weight. The high rate of complications at pregnancy and the puerperium in Afghanistan could have many causes, including lack of access to skilled birth attendants during delivery and high remoteness (Barlett et al. 2005), home delivery (Nelson 2011), poor sanitation, and lack of access to clean and safe drinking water (Amowitz et al. 2002).

Our findings also indicated heterogeneity in the geographical distribution of causes of death, and was confirmed by significant correlation between random effects. Accounting for the withinsubject association between causes of death improved the parameter estimates, this improvement was confirmed by smaller AIC. This is consistent with our findings that mothers living in remote and rural areas are prone to complications at birth. The observed geographical differences in the mortality rates could be a result of the barely functional health care system in Afghanistan, especially in the rural areas (high mortality rates are observed in the rural areas). The supply of trained health personnel is almost non-existent in the rural areas, and about 75 per cent of the physicians in Afghanistan are concentrated around Kabul (Prasad 2006).

We acknowledge the following limitations in our study: Firstly, in collecting information through VA, the assessment is based on the respondents' ability to provide an adequate account of the death process. The enquiries about the death may be upsetting, especially in a very sensitive society, thereby raising the issue of the reliability of the data. In developing countries, though, where death certificates are lacking for the majority of the population, VA is very crucial for investigations into causes of death. Secondly, although there is a strong correlation between COMPLICATIONS $=1$ and SYMPTOMS $=1$, this may not be true for other possible combinations. Besides, there may be other disease classifications that are acting as a confounding factor. Finally, although the use of the ICD is to reduce the number of diseases and complexity with the analysis, the classification may be too broad to pinpoint the specific disease(s).

In spite of the abovementioned limitations, the use of the spatial bivariate probit model for joint analysis of multiple causes of death provides an opportunity to investigate the influence of both the individual- and province-level risk factors on mortality. It also allows for accounting for dependency at both levels of the data (Neelon et al. 2012). This model is superior to the univariate model when the outcomes are correlated. The model provides an opportunity for a flexible tool for joint analysis using random-effects models. The extension of the bivariate probit model to account for geographical heterogeneity through random effects provides an avenue to model the dependency in our data, and allowed for the possibility to estimate the extent of correlation between the different causes of death. The approach not only indicates the dependence of the responses on the demographic variables and other risk factors, it also provides additional information about the relationship between complications and symptoms. 
Adegboye and Kotze: Causes and patterns of morbitidy and mortality in Afghanistan

The effect of socioeconomic status of the family on mortality cannot be overemphasized, when the struggle for food and other resources for child survival is so overwhelming, especially in rural areas. The disparity between socioeconomic groups in Afghanistan is mind-boggling, with two-thirds of urban households falling into the richest quintile (APHI/MoPH et al. 2011). This study revealed that remoteness, place of residence, and wealth index play a significant role in increasing neonatal deaths in Afghanistan.

About 46 per cent of the households in this study do not have access to safe drinking water, and only one-fifth of households have an improved toilet facility. Good hygiene is crucial and a simple way of combating many diseases; also, maternal access to health services has been shown to have a positive impact on child survival (Kayode et al. 2012). Previous studies have reported that poor sanitation and lack of access to clean water have an indirect relation to high infant mortality (Amowitz et al. 2002). The chance of complications of pregnancy or at birth is higher for households with poor sanitation. The same can said about households without access to safe drinking water.

In conclusion, we have presented our analysis of multiple causes of death using three models. This study has shown that accounting for correlations between multiple causes of death provides better results and precise parameter estimates. The models were assessed by AIC, indicating that the model which analyzes two causes of death simultaneously (jointly) has the smallest AIC. We have seen significant differences in mortality rates across Afghanistan and the role played by the remoteness index, especially as related to complications during pregnancy and childbirth. The study has revealed that size at birth, remoteness index, residence, age of the child, wealth index, sanitation, and duration of pregnancy are important predictors of diseases classified as complications, while age, size at birth, place of birth, and duration of pregnancy are strongly associated with diseases classified as symptoms. This study is quite novel, because the dependency between two causes of death has not been exploited before in Afghanistan. The findings provide the possibility of simultaneously looking into issues of multiple causes of death in Afghanistan.

\section{Acknowledgments}

The authors would like to acknowledge the American University of Afghanistan for making this research possible through the 2012 AUAF Research Fellowship. This research was initiated and completed while the lead author was a faculty member in the Department of Science and Mathematics, American University of Afghanistan, Kabul. The lead author would like to thank his research assistant Sayed Elyas Najafizada for the data management. The authors also thank the reviewers for their constructive comments, which greatly improved the article. A short version of this paper was presented at the 2013 Annual Meeting of the Population Association of America.

\section{References}

APHI/MoPH et al. (Afghan Public Health Institute, Ministry of Public Health [Afghanistan], Central Statistics Organization (CSO) [Afghanistan], ICF Macro, Indian Institute of Health Management Research (IIHMR) [India], and World Health Organization Regional Office for the Eastern Mediterranean (WHO/EMRO) [Egypt]). 2011. Afghanistan Mortality Survey 2010. Calverton, MD: APHI/MoPH, CSO, ICF Macro, IIHMR and WHO/EMRO. 
Amowitz, L.L., C. Reis, and V. Jacopino. 2002. Maternal mortality in Herat province, Afghanistan, in 2002: An indicator of women's human rights. Journal of the American Medical Association 288(10):1284-1291.

Bapat, U., G. Alcock, N. More, S. Das, W. Joshi, and D. Osrin. 2012. Stillbirths and newborn deaths in slum settlements in Mumbai, India: A prospective verbal autopsy study. BMC Pregnancy and Childbirth 12.

Bartlett, L.A., S. Mawji, S. Whitehead, C. Crouse, S. Dalil, D. Ionete, P. Salama, and the Afghan Maternal Mortality Study Team. 2005. Where giving birth is a forecast of death: Maternal mortality in four districts of Afghanistan, 1999-2002. The Lancet 365:864-870.

Bhutta, Z. 2002. Children of war: The real casualties of the Afghan conflict. British Medical Journal 324:349-352.

Bickel, P., C.A.J. Klaassen, Y. Ritov, and J.A. Wellner. 2006. Disease and Mortality in Sub-Saharan Africa. Washington: World Bank.

Fauveau, V. 2005. The study of causes of death in developing countries, in Demography: Analysis and Synthesis, edited by G. Wunsch, G. Caselli, and J. Vallin. vol. 2. New York: Elsevier.

Garenne, M., and V. Fauveau. 2006. Potential and limits of verbal autopsies. Bulletin of the World Health Organization 84:3.

Gessner, B.D. 1994. Mortality rates, causes of death, and health status among displaced and resident populations of Kabul, Afghanistan. Journal of the American Medical Association 272:382-385.

Kayode, G.A., V.T. Adekanmbi, and O.A. Uthman. 2012. Risk factors and a predictive model for underfive mortality in Nigeria: Evidence from Nigeria Demographic and Health Survey. BMC Pregnancy and Childbirth 12.

Kim, Y., H. Tappis, P. Zainullah, N. Ansari, C. Evans, L. Bartlett, N. Zaka, and W. Zeck. 2012. Quality of caesarean delivery services and documentation in first-line referral facilities in Afghanistan: A chart review. BMC Pregnancy and Childbirth 12.

King, G., and Y. Lu. 2008. Verbal autopsy methods with multiple causes of death. Statistical Science 23:78-91.

Lee, A., L. Mullany, J. Tielsch, J. Katz, S. Khatry, S. LeClerq, R. Adhikari, S. Shrestha, and G. Darmstadt. 2008. Verbal autopsy methods to ascertain birth asphyxia deaths in a community-based setting in Southern Nepal. Pediatrics 121.

Lesaffre, E., and G. Molenberghs. 1991. Multivariate probit analysis: A neglected procedure in medical statistics. Statistics in Medicine 10:1391-1403.

Mayhew, M., P.M. Hansen, D.H. Peters, A. Edward, L.P. Singh, V. Dwivedi, A. Mashkoor, and G. Burnham. 2008. Determinants of skilled birth attendant utilization in Afghanistan: A crosssectional study. American Journal of Public Health 98(10):1850-1856.

Neelon, B., R. Anthopolos, and M. Miranda. 2012. A spatial bivariate probit model for correlated binary data with application to adverse birth outcomes. Statistical Methods in Medical Research. doi: 10.1177/0962280212447149. 
Adegboye and Kotze: Causes and patterns of morbitidy and mortality in Afghanistan

Philip, W.S., S. Osman, R. Chalapati, A.V. Victoria, M. Colin, G. Yang, H. Yusuf, J. Prabhat, and D.L. Alan. 2005. Sample registration of vital events with verbal autopsy: A renewed commitment to measuring and monitoring vital statistics. Bulletin of the World Health Organization 83:611-617.

Prasad, A. 2006. Disease profile of children in Kabul: The unmet need for health care. Journal of Epidemiology and Community Health 60:20-23.

Quigley, M.A. 2005. Commentary: Verbal autopsies from small-scale studies to mortality surveillance systems. International Journal of Epidemiology 34:1087-1088.

Sibai, A.M., A. Fletcher, M. Hills, and O. Campbell. 2001. Non-communicable disease mortality rates using the verbal autopsy in a cohort of middle aged and older populations in Beirut during wartime, 1983-93. Journal of Epidemiology and Community Health 55:271-276.

Stallard, E. 2002. Underlying and multiple cause mortality at advanced ages: United States 1980-1998. North America Actuarial Journal 6(3).

WHO (World Health Organization). 1978. Lay Reporting of Health Information. Geneva: World Health Organization.

- 1995. Verbal Autopsies for Maternal Deaths. Geneva: World Health Organization.

. 2011. International Statistical Classification of Diseases and Related Health Problems. 10th revision. Geneva: World Health Organization. 